\title{
Impact of the 8th edition of the AJCC TNM classification on gastric cancer prognosis-study of a western cohort
}

\author{
Mariana Peyroteo ${ }^{1 a}$ iD , Pedro Carvalho Martins ${ }^{1}$, Rita Canotilho ${ }^{1}$, Ana Margarida Correia ${ }^{1}$, Catarina Baía ${ }^{1}$, Alexandre Sousa ${ }^{1}$, Donzília \\ Brito $^{1}$, José Flávio Videira ${ }^{1}$, Lúcio Lara Santos ${ }^{1,2}$ and Abreu de Sousa ${ }^{1}$
}

${ }^{1}$ Surgical Oncology Department, Instituto Português de Oncologia do Porto Francisco Gentil, EPE, Porto, 4200-072, Portugal ${ }^{2}$ Experimental Pathology and Therapeutics Group, Instituto Português de Oncologia do Porto Francisco Gentil, EPE, Porto, 4200-072, Portugal ahttps://orcid.org/0000-0002-0941-2533

\section{Abstract}

Introduction: The 8th edition of the American Joint Committee on Cancer (AJCC) TNM classification for gastric cancer introduced changes, mainly in stage III, with the incorporation of the pN3 sub-classification in the final staging group. The goal was to compare the 7 th and 8th editions to evaluate the discriminative capacity of the new edition.

Methods: This study was a retrospective review of patients with gastric cancer treated with surgery in 2013 and 2014.

Results: We analysed 310 patients, with a median age of 66 years and out of which $55.5 \%$ were male. The most commonly performed surgery was subtotal gastrectomy $(n=$ 158; 51\%), with a median of 30 lymph nodes removed. With a median follow-up of 39.5 months, the 1- and 3-year overall survival (OS) was $82 \%$ and $59 \%$, respectively. In stage III $(n=115)$, there was stage migration in 40 cases (34.8\%), with upstage in 11 cases and downstage in 29 cases. In this group, there was a statistically significant difference in OS between $\mathrm{N} 3 \mathrm{a}$ and $\mathrm{N} 3 \mathrm{~b}$ patients $(p=0.002)$, as well as a statistically significant difference in OS between stages IIIA, IIIB and IIIC when the 8th edition was applied ( $p=0.001$ ), which was not verified with the 7th edition $(p=0.057)$. In multivariate analysis, both extracapsular extension and $\mathrm{N}$ classification from TNM were independent prognostic factors ( $p=0.033$ and $p=0.024$, respectively).

Conclusion: The 8th edition of the AJCC TNM classification allows for a better prognostic refinement, namely in the new stage III groups after the stratification of lymph node disease in N3a and N3b. Factors that evaluate the biological behaviour of the disease remain excluded from this edition, such as extracapsular extension, which had a prognostic impact in our series.

Keywords: gastric cancer, staging, eighth edition TNM classification, AJCC

\section{Background}

Gastric cancer is the fifth most common malignant tumour worldwide, as well as the third cause of cancer-related mortality [1-3]. Despite the evolution of the treatment strategy

Correspondence to: Mariana Peyroteo Email: mariana.peyroteo@gmail.com

ecancer 2020, 14:1124

https://doi.org/10.3332/ecancer.2020.1124

Published: $15 / 10 / 2020$

Received: 23/05/2020

Publication costs for this article were supported by ecancer (UK Charity number 1176307).

Copyright: $@$ the authors; licensee ecancermedicalscience. This is an Open Access article distributed under the terms of the Creative Commons Attribution License (http:// creativecommons.org/licenses/by/3.0), which permits unrestricted use, distribution, and reproduction in any medium, provided the original work is properly cited. 
in recent decades, namely, with the association of perioperative chemotherapy, prognosis remains poor, especially in locally advanced disease [4-6].

The American Joint Committee on Cancer (AJCC) TNM staging system is the most frequently used staging method for malignant diseases. The 8th edition of the AJCC classification for gastric cancer introduced significant changes, mainly in stage III [7, 8]. Stage I remained unchanged, but in stage II there was a migration of T1N3bM0 patients from stage IIB to IIIB. Regarding stage III, although in the 7th edition the N3 group was divided between N3a (7-15 positive lymph nodes) and N3b (more than 15 positive lymph nodes), this subdivision was not taken into account in the final staging. In the 8th edition, this N3 group subdivision was incorporated in order to improve survival stratification in these patients. On the other hand, in contrast to other malignant tumours like breast cancer, other factors that could allow for a better prognostic refinement, namely related to the biological behaviour of the disease, remain excluded from this revision of the AJCC classification for gastric cancer [8].

The main goal of this study was to compare the 7th and 8th editions of the AJCC TNM classification for gastric cancer in order to determine the proportion of patients in which stage migration would occur and to determine if the greater prognostic refinement introduced by the new edition would be verified in our population. The secondary goal was to establish prognostic factors that could improve the discriminative power of this classification.

\section{Methods}

The data from all patients with gastric adenocarcinoma consecutively treated with surgery at Instituto Português de Oncologia do Porto, EPE, between January 2013 and December 2014, were retrospectively reviewed. All adult patients ( $\geq 18$ years old) with histologic confirmation of adenocarcinoma who submitted to surgery with curative intent were included. Exclusion criteria were stage IV at diagnosis, recurrent gastric cancer, other synchronous malignant tumours or oesophagogastric junction tumours of Siewert types I and II [9].

Data regarding demographic features, treatment, histology and follow-up were recorded. The type of lymph node dissection carried out was classified according to the Japanese Gastric Cancer Association classification [10].

Statistical analysis was carried out with version 24 of the SPSS ${ }^{\circledR}$ software, with a $p<0.05$ considered as statistically significant. Continuous variables were presented as median and range. Categorical variables were analysed using Pearson $\chi^{2}$ test or Fisher's exact test as appropriate. Tumours were staged according to the 7th and 8th editions of the AJCC TNM classification for gastric cancer [7, 8]. Kaplan-Meier's survival curves were built and stratified according to both editions and compared using the log-rank test.

A univariate analysis was carried out in stage III patients to test the association between potential prognostic factors (independent variables) and the dependent variable, which was overall survival (OS) in this study. The analysed independent variables were age, gender, type of lymph node dissection, number of removed lymph nodes, lymphovascular invasion in the primary tumour, perineural invasion in the primary tumour, T and N classification of the TNM system and extracapsular extension in removed lymph nodes. The factors that achieved statistical significance in the univariate analysis were used to build the multivariate analysis model, through Cox regression, with hazard ratio (HR) and the respective $95 \%$ confidence intervals $(95 \% \mathrm{Cl})$ reported.

\section{Results}

A total of 310 patients were included in the analysis, out of which $55.5 \%(n=172)$ were male patients. The median age was 66 years (range: 24-89). The characteristics of the study group are described in Table 1.

The surgery performed was subtotal gastrectomy in $51 \%(n=158)$ of cases, total gastrectomy in $47.1 \%(n=146)$ and other types of surgery in 1.3\% $(n=6)$, specifically gastrectomy totalisations (after previous antrectomy for peptic ulcer disease) and one superior polar gastrectomy (fundus and corpus resection for a proximal gastric tumour). The type of lymph node dissection was specified in 74.8\% $(n=232)$ of cases, with D2 lymphadenectomy made in $36.2 \%(n=84)$ of cases, D1+ in $60.8 \%(n=141)$ and D1 in $3 \%(n=7)$. Neoadjuvant chemotherapy was carried out in $6.5 \%(n=20)$ of the patients and adjuvant chemotherapy in $31.7 \%(n=98)$. 
Table 1. Descriptive characteristics of the study cohort (IQR: interquartile range; $\mathrm{N}^{\circ}$ : number).

\begin{tabular}{|c|c|}
\hline Characteristics & Values \\
\hline Age, years, median (IQR) & $66(57-74)$ \\
\hline $\begin{array}{l}\text { Gender, } n(\%) \\
\text { Female } \\
\text { Male }\end{array}$ & $\begin{array}{l}138(44.5 \%) \\
172(55.5 \%)\end{array}$ \\
\hline $\begin{array}{l}\text { Type of gastric surgery, } n(\%) \\
\text { Subtotal gastrectomy } \\
\text { Total gastrectomy } \\
\text { Other procedures }\end{array}$ & $\begin{array}{l}158(51 \%) \\
146(47.1 \%) \\
6(1.9 \%)\end{array}$ \\
\hline $\begin{array}{l}\text { Type of lymph node dissection }(n=232), n(\%) \\
\text { D2 } \\
\text { D1+ } \\
\text { D1 }\end{array}$ & $\begin{array}{l}84(36.2 \%) \\
141(60.8 \%) \\
7(3 \%)\end{array}$ \\
\hline $\begin{array}{l}\text { Neoadjuvant chemotherapy, } n(\%) \\
\text { No } \\
\text { Yes }\end{array}$ & $\begin{array}{l}290(93.5 \%) \\
20(6.5 \%)\end{array}$ \\
\hline $\begin{array}{l}\text { Adjuvant chemotherapy, } n \text { (\%) } \\
\text { No } \\
\text { Yes }\end{array}$ & $\begin{array}{l}212 \text { (68.3\%) } \\
98(31.7 \%)\end{array}$ \\
\hline Size of the tumour, $\mathrm{cm}$, median (IQR) & $4.5(3-7)$ \\
\hline $\begin{array}{l}\text { Lymphovascular invasion, } n(\%) \\
\text { No } \\
\text { Yes }\end{array}$ & $\begin{array}{l}117(37.8 \%) \\
193(62.2 \%)\end{array}$ \\
\hline $\begin{array}{l}\text { Perineural invasion, } n(\%) \\
\text { No } \\
\text { Yes }\end{array}$ & $\begin{array}{l}167(53.9 \%) \\
143(46.1 \%)\end{array}$ \\
\hline $\begin{array}{l}\text { Multifocality, } n(\%) \\
\text { No } \\
\text { Yes }\end{array}$ & $\begin{array}{l}295(95.2 \%) \\
15(4.8 \%)\end{array}$ \\
\hline $\begin{array}{l}\text { Histological subtype, } n(\%) \\
\text { Intestinal } \\
\text { Mixed } \\
\text { Signet ring cells } \\
\text { Mucinous }\end{array}$ & $\begin{array}{l}171(55.2 \%) \\
72(23.2 \%) \\
64(20.6 \%) \\
3(1 \%)\end{array}$ \\
\hline $\begin{array}{l}\text { pT, } n(\%) \\
\text { pT1a } \\
\text { pT1b } \\
\text { pT2 } \\
\text { pT3 } \\
\text { pT4a } \\
\text { pT4b }\end{array}$ & $\begin{array}{l}32(10.3 \%) \\
58(18.7 \%) \\
54(17.4 \%) \\
100(32.2 \%) \\
59(19 \%) \\
7(2.3 \%) \\
\end{array}$ \\
\hline $\mathrm{N}^{\circ}$ of retrieved lymph nodes, median (IQR) & $30(23-40)$ \\
\hline $\mathrm{N}^{\circ}$ of positive lymph nodes, median (IQR) & $5(0-5)$ \\
\hline $\begin{array}{l}\mathrm{pN}, n(\%) \\
\mathrm{pN} 0 \\
\mathrm{pN} 1 \\
\mathrm{pN} 2 \\
\mathrm{pN} 3 \mathrm{a} \\
\mathrm{pN} 3 \mathrm{~b}\end{array}$ & $\begin{array}{l}147(47.4 \%) \\
57(18.4 \%) \\
34(11 \%) \\
49(15.8 \%) \\
23(7.4 \%)\end{array}$ \\
\hline
\end{tabular}


Regarding histological analysis, the median tumour size was $4.5 \mathrm{~cm}$ (range: $0.99-16.5$ ), with lymphovascular invasion in $62.3 \%$ ( $n=193$ ) of tumours and perineural invasion in $46.1 \%(n=143)$. Multifocality was found in $4.8 \%(n=15)$ of cases and the most common histological subtype was intestinal (55.2\%; $n=171)$. Concerning pathological staging, $29 \%(n=90)$ of tumours were classified as pT1 (32 as pT1a and 58 as pT1b), $17.4 \%(n=54)$ as pT2, 32.3\% $(n=100)$ as pT3 and $21.3 \%(n=66)$ as pT4 (59 as pT4a and 7 as pT4b).

A median of 30 lymph nodes (range: 5-95) was retrieved in the lymph node dissection product, with $52.6 \%(n=163)$ of patients with positive lymphadenectomies, with a median of five positive lymph nodes (range: $0-65$ ). Extracapsular extension was identified in $26 \%$ ( $n=75$ ) of cases. Regarding pathological staging, $47.4 \%(n=147)$ of tumours were classified as pN0, $18.4 \%(n=57)$ as pN1, 11\% $(n=34)$ as pN2 and $23.2 \%(n=72)$ as pN3 (49 as pN3a and 23 as pN3b).

The distribution of stage groups according to the 7th and 8th editions of the AJCC TNM classification is shown in Figure 1. The distribution in our cohort was as follows: stage I, 38.7\% ( $n=120)$ of cases; stage II, $24.2 \%(n=75)$; and stage III, $37.1 \%(n=115)$. Regarding stage migration, there were no changes between the two editions in stages I and II. Differences in staging from the 7th to 8th edition were verified in 40 patients (12.9\%), all in stage III, with upstage in 11 cases (two from IIIA to IIIB and nine from IIIB to IIIC) and downstage in 29 cases (12 from IIIB to IIIA and 17 from IIIC to IIIB).

With a median follow-up of 39.5 months, 1- and 3-year OS was $82 \%$ and 59\%, respectively. When stratified by stage groups, the 3-year OS was $87 \%$ in stage I, 79\% in stage II and $21 \%$ in stage III, with a statistically significant difference in OS between stages ( $p<0.001$ ) (Figure 2 ).

In the sub-analysis of stage III patients $(n=115)$, there was a statistically significant difference in OS between N3a and N3b patients $(p=$ 0.001) (Figure 3). A statistically significant difference in OS between stages IIIA, IIIB and IIIC was found when the 8th edition was applied $(p=0.001$ ), but not when the 7th edition was used ( $p=0.057)$, (Figures 4 and 5$)$. In the univariate analysis of potential prognostic factors in stage III patients $(n=115)$, extracapsular extension and the number of positive lymph nodes ( $N$ classification form TNM) had a statistically significant relationship with OS ( $p=0.02$ and $p=0.007$, respectively). In multivariate analysis, both of these factors (extracapsular extension and $\mathrm{N}$ classification from TNM) were independent prognostic factors ( $p=0.033$ and $p=0.024$, respectively), (Table 2).

$7^{\text {th }}$ Edition TNM staging $\quad 8^{\text {th }}$ Edition TNM staging

\begin{tabular}{|c|c|c|c|c|}
\hline Stage & $\begin{array}{c}\text { № of } \\
\text { patients }\end{array}$ & & Stage & $\begin{array}{c}\text { № of } \\
\text { patients }\end{array}$ \\
\hline IA (76) & 76 & & 76 & IA (76) \\
\hline IB (44) & 44 & & 44 & IB (44) \\
\hline IIA (43) & 43 & & 43 & IIA (43) \\
\hline IIB (32) & 32 & - & 32 & IIB (32) \\
\hline \multirow{2}{*}{ IIIA (34) } & 32 & 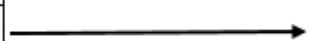 & 32 & \multirow{2}{*}{ IIIA (44) } \\
\hline & 2 & & 12 & \\
\hline \multirow{3}{*}{ IIIB (50) } & 29 & & 29 & \multirow{3}{*}{ IIIB (48) } \\
\hline & 12 & & 2 & \\
\hline & 9 & & 17 & \\
\hline \multirow{2}{*}{ IIIC (31) } & 14 & & 14 & \multirow{2}{*}{ IIIC (23) } \\
\hline & 17 & & 9 & \\
\hline
\end{tabular}

Figure 1. Distribution according to the 7th and 8th editions of the AJCC TNM classification ( $N^{\circ}$ : number). 

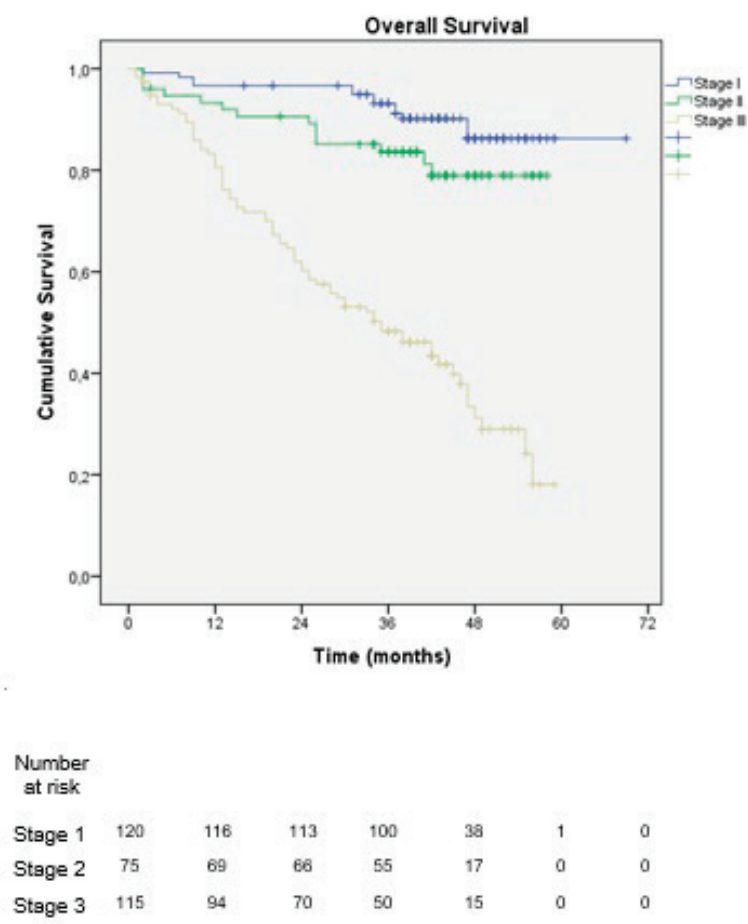

Figure 2. Overall survival stratified by staging according to the 8th edition of the AJCC TNM classification.

\section{Discussion}

The 8th edition of the AJCC TNM classification introduced important changes, mainly in stage III patients, with the incorporation of the N3a and N3b subdivision in the final staging [8]. In our series, stage III corresponded to a significant percentage of patients (37.1\%), being the only stage where migration occurred. In fact, there was a statistically significant difference in OS between N3a and N3b patients, which probably explains the 40 cases (12.9\%) of stage migration in stage III (upstage in 11 cases and downstage in 29 cases).

The new edition of the AJCC TNM classification for gastric cancer was largely based on the proposal by Sano et al [11], which was based on a mostly eastern population, raising the question of its applicability in western populations, which is similar to what happened in the transition from the 6th to 7 th edition of the classification $[12,13]$. However, the greater discriminative power of the 8th edition was verified in our cohort by the statistically significant difference in OS between stages IIIA, IIIB and IIIC, which was demonstrated when the 8th edition was applied $(p=0.001)$ but not when the 7th edition was used $(p=0.057)$. The present series is one of the few studies, together with Haejin In et al [14] and Graziosi et al [15], that evaluated western populations and came to similar conclusions.

The changes introduced by the new edition of the classification reinforce the importance of lymph node metastasis as a prognostic factor in gastric cancer and, in consequence, of the number of lymph nodes retrieved as an essential factor for accurate staging [16-20]. In fact, despite still not clearly establishing the minimum number of lymph nodes that should be retrieved in surgery, the inclusion of the subdivisions N3a and N3b in the final staging implies the resection of at least 15 lymph nodes in order for the N3b classification to be attributed. In our series, a median of 30 lymph nodes was retrieved, which follows the trend of this new edition regarding the better discriminative power associated to more extensive lymphadenectomies. This was also verified in the series by Lu et al [21], with the finding that the 8th edition of the classification had a slightly greater discriminative power when $>30$ lymph nodes were removed. 


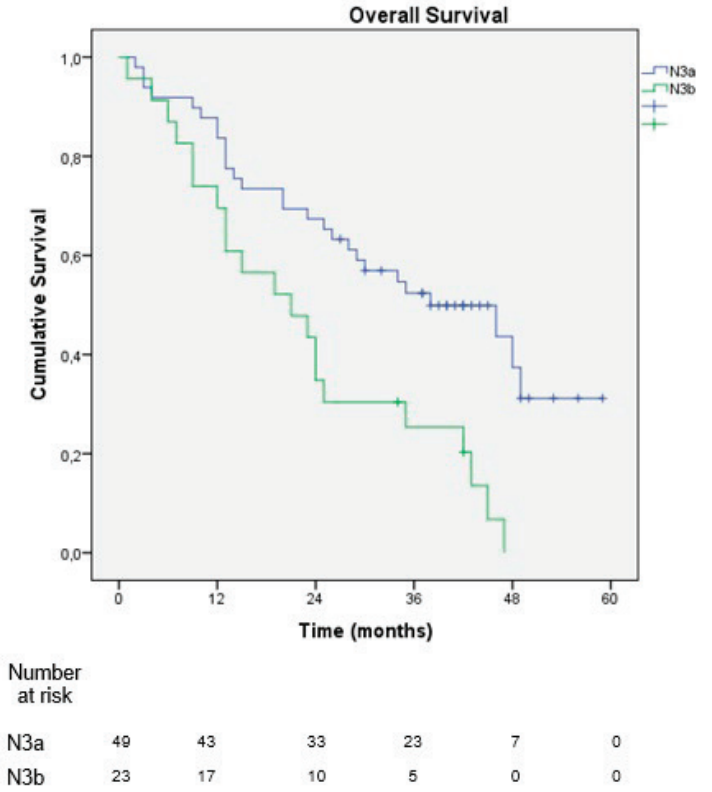

Figure 3. Overall survival stratified by the subdivisions N3a and N3b of the 8th edition of the AJCC TNM classification.

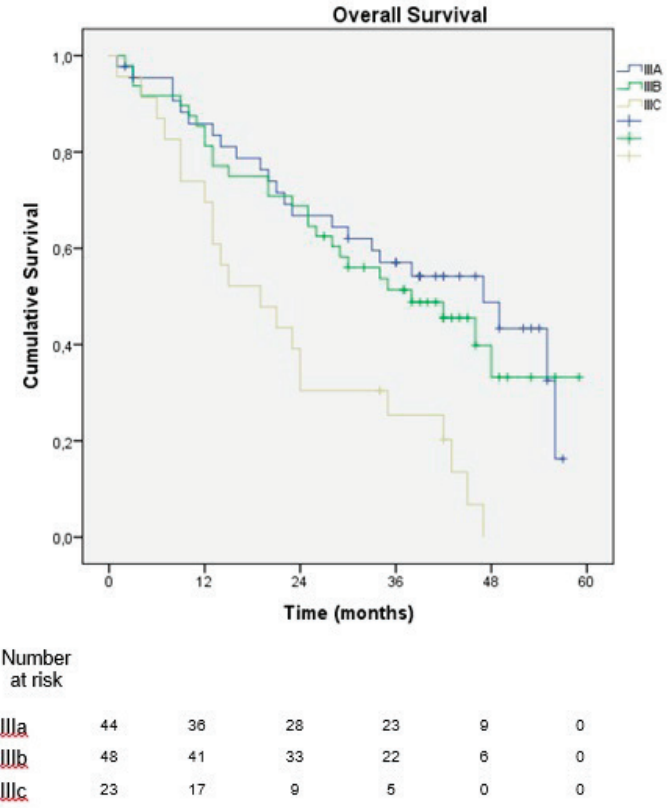

Figure 4. Overall survival of stage III patients according to the 8th edition of the AJCC TNM classification. 


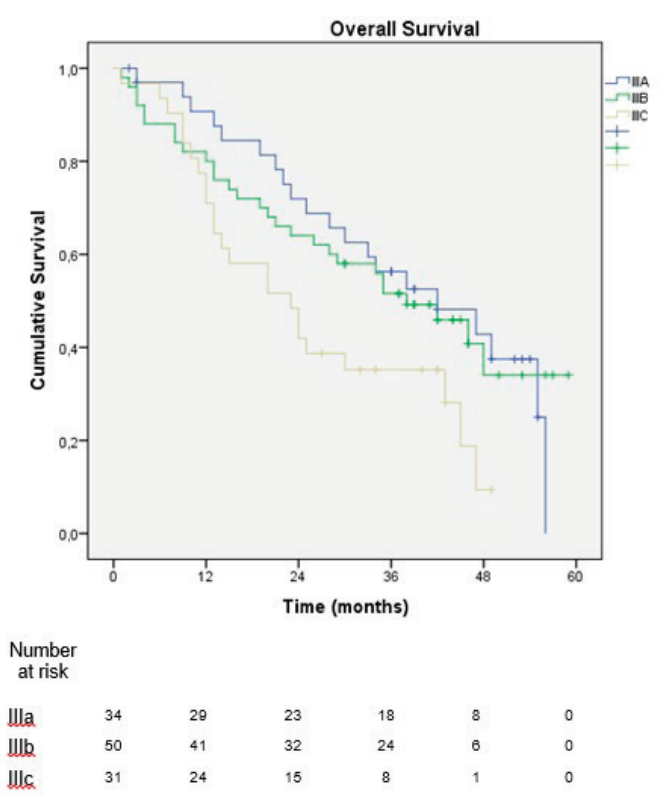

Figure 5. Overall survival of stage III patients according to the 7th edition of the AJCC TNM classification.

Table 2. Univariate and multivariate analysis of prognostic factors for OS (Cl: confidence interval; HR: hazard ratio; $\mathrm{N}^{\circ}$ : number).

\begin{tabular}{|c|c|c|c|c|}
\hline \multicolumn{5}{|c|}{ Prognostic factors for OS } \\
\hline & \multicolumn{2}{|c|}{ Univariate analysis } & \multicolumn{2}{|c|}{ Multivariate analysis } \\
\hline & $\mathrm{HR}(95 \% \mathrm{Cl})$ & $p$-value & HR $(95 \% \mathrm{Cl})$ & $p$-value \\
\hline Age & $1.01(0.99-1.03)$ & $p=0.411$ & & \\
\hline Gender (male) & $1.22(0.75-1.97)$ & $p=0.423$ & & \\
\hline Lymphovascular invasion & $1.54(0.67-3.56)$ & $p=0.315$ & & \\
\hline Perineural invasion & $1.30(0.74-2.27)$ & $p=0.367$ & & \\
\hline Size of tumour $(\geq 4.5 \mathrm{~cm})$ & $1.18(0.69-2.04)$ & $p=0.549$ & & \\
\hline $\begin{array}{l}\text { Type of lymph node dissection } \\
\text { D1 } \\
\text { D1+ } \\
\text { D2 }\end{array}$ & $\begin{array}{c}1 \\
0.32(0.10-1.07) \\
0.36(0.11-1.21)\end{array}$ & $p=0.179$ & & \\
\hline $\mathrm{N}^{\circ}$ of lymph nodes removed $(\geq 30)$ & $0.88(0.55-1.42)$ & $p=0.598$ & & \\
\hline Extracapsular extension & $1.96(1.11-3.45)$ & $p=0.020$ & $1.84(1.02-3.32)$ & $p=0.033$ \\
\hline $\begin{array}{l}\text { T } \\
\text { T2 } \\
\text { T3 } \\
\text { T4a } \\
\text { T4b }\end{array}$ & $\begin{array}{c}1 \\
1.04(0.25-4.35) \\
1.70(0.41-7.11) \\
1.08(0.10-5.93) \\
\end{array}$ & $p=0.236$ & & \\
\hline $\begin{array}{l}\text { N } \\
\text { N0 } \\
\text { N1 } \\
\text { N2 } \\
\text { N3a } \\
\text { N3b }\end{array}$ & $\begin{array}{c}1 \\
2.95(0.38-23.28) \\
1.70(0.22-13.33) \\
2.29(0.31-17.09) \\
5.52(0.72-42.13)\end{array}$ & $p=0.007$ & $\begin{array}{c}1 \\
2.08(0.25-17.02) \\
0.86(0.10-7.22) \\
0.88(0.10-7.48) \\
1.33(0.13-13.37)\end{array}$ & $p=0.024$ \\
\hline
\end{tabular}


On the other hand, the new edition still excludes other prognostic factor that could contribute to a better prognostic refinement. Specifically, in our series, extracapsular extension was an independent prognostic factor. Extracapsular extension has been previously established as a poor prognostic factor both in early and advanced stages of gastric cancer [22, 23], with potential implications in adjuvant chemotherapy indications in early stages [24]. So, these findings suggest that this could be a factor to include in future revisions of the classification, since it is easily accessible information through histological observation alone. Besides, the inclusion of other factors related to the biological behaviour of the disease in the staging system could help select patients for adjuvant/perioperative chemotherapy, as well as define the adequate type of lymphadenectomy, since despite the changes introduced by the new edition, these do not have implications in defining the treatment strategy as yet.

One of the main limitations of this study is related to its retrospective nature, which explains why we did not have access to all the registries of the type of lymphadenectomy carried out. In patients where we could define the type of lymphadenectomy, D2 dissection was carried out in only $36.2 \%$ of cases and D1+ was carried out in the majority of patients (60.8\%). This is related to the evidence available at the time of the study period, establishing that D2 dissection was not superior to D1+ in terms of OS [25]. In addition, the median of 30 lymph nodes resected attests to a good lymphadenectomy in our patients.

Finally, other limitations are related to the study being unicentric, with a follow-up time that can be insufficient for bigger conclusions and with the inclusion of few patients submitted to perioperative chemotherapy, which is related to the study period and may influence the survivals presented. On the other hand, it paints a better picture of the natural behaviour of this disease, with the possibility of serving as a benchmark for future studies.

\section{Conclusion}

The new staging system introduced by the 8th edition of the AJCC TNM classification adds value and discriminative power in comparison to the previous edition in patients with gastric adenocarcinoma treated with surgery. This represents a significant improvement, especially in stage III patients, due to the better stratification of lymph node disease between N3a and N3b. However, these efforts did not go as far as what was presented for other malignancies in this edition, and it was demonstrated here that the inclusion of other factors that evaluate the biological behaviour of this disease, like extracapsular extension, could have further refined this tool.

\section{Conflicts of interest}

The authors have no conflicts of interest to declare.

\section{Funding}

There is no funding to declare.

\section{Authors' contributions}

MP and AS idealised the study concept, designed the methodology and wrote the article. PCM contributed to revising the article and statistical analysis. RC, AMC and CB contributed to writing the first draft of the article. DB, JFV, LLS and ADS reviewed the final draft of the article. 


\section{References}

1. Crew KD and Neugut Al (2006) Epidemiology of gastric cancer World J Gastroenterol 12(3) 354-362 https://doi.org/10.3748/wjg.v12. i3.354 PMID: 16489633 PMCID: 4066052

2. Sitarz R, Skierucha M, and Mielko J, et al (2018) Gastric cancer: epidemiology, prevention, classification, and treatment Cancer Manag Res 10 239-248 https://doi.org/10.2147/CMAR.S149619 PMID: 29445300 PMCID: 5808709

3. Bray F, Ferlay J, and Soerjomataram I, et al (2018) Global cancer statistics 2018: GLOBOCAN estimates of incidence and mortality worldwide for 36 cancers in 185 countries CA Cancer J Clin 68(6) 394-424 https://doi.org/10.3322/caac.21492 PMID: 30207593

4. Al-Batran SE, Hofheinz RD, and Pauligk C, et al (2016) Histopathological regression after neoadjuvant docetaxel, oxaliplatin, fluorouracil, and leucovorin versus epirubicin, cisplatin, and fluorouracil or capecitabine in patients with resectable gastric or gastro-oesophageal junction adenocarcinoma (FLOT4-AIO): results from the phase 2 part of a multicentre, open-label, randomised phase $2 / 3$ trial Lancet Oncol 17(12) 1697-1708 https://doi.org/10.1016/S1470-2045(16)30531-9 PMID: 27776843

5. Al-Batran SE, Homann N, and Pauligk C, et al (2019) Perioperative chemotherapy with fluorouracil plus leucovorin, oxaliplatin, and docetaxel versus fluorouracil or capecitabine plus cisplatin and epirubicin for locally advanced, resectable gastric or gastro-oesophageal junction adenocarcinoma (FLOT4): a randomised, phase 2/3 trial Lancet 393(10184) 1948-1957 https://doi.org/10.1016/S01406736(18)32557-1 PMID: 30982686

6. Cunningham D, Allum WH, and Stenning SP, et al (2006) Perioperative chemotherapy versus surgery alone for resectable gastroesophageal cancer N Engl J Med 355(1) 11-20 https://doi.org/10.1056/NEJMoa055531 PMID: 16822992

7. Edge SB and Compton CC (2010) The American Joint Committee on Cancer: the 7th edition of the AJCC cancer staging manual and the future of TNM Ann Surg Oncol 17(6) 1471-1474 https://doi.org/10.1245/s10434-010-0985-4 PMID: 20180029

8. Amin MB, Greene FL, and Edge SB, et al (2017) The Eighth Edition AJCC Cancer Staging Manual: Continuing to build a bridge from a population-based to a more "personalized" approach to cancer staging CA Cancer J Clin 67(2) 93-99 https://doi.org/10.3322/ caac.21388 PMID: 28094848

9. Siewert JR, Stein HJ, and Feith M (2006) Adenocarcinoma of the esophago-gastric junction Scand J Surg 95(4) 260-269 https://doi. org/10.1177/145749690609500409

10. Japanese Gastric Cancer A (2011) Japanese gastric cancer treatment guidelines 2010 (ver. 3) Gastric Cancer 14(2) 113-123 https://doi. org/10.1007/s10120-011-0042-4

11. Sano T, Coit DG, and Kim HH, et al (2017) Proposal of a new stage grouping of gastric cancer for TNM classification: International Gastric Cancer Association staging project Gastric Cancer 20(2) 217-225 https://doi.org/10.1007/s10120-016-0601-9

12. Marano L, Boccardi V, and Braccio B, et al (2015) Comparison of the 6th and 7th editions of the AJCC/UICC TNM staging system for gastric cancer focusing on the "N" parameter-related survival: the monoinstitutional NodUs Italian study World J Surg Oncol 13215 https://doi.org/10.1186/s12957-015-0633-3 PMID: 26179492 PMCID: 4504099

13. McGhan LJ, Pockaj BA, and Gray RJ, et al (2012) Validation of the updated 7th edition AJCC TNM staging criteria for gastric adenocarcinoma J Gastrointest Surg 16(1) 53-61 discussion https://doi.org/10.1007/s11605-011-1707-3

14. In H, Solsky I, and Palis B, et al (2017) Validation of the 8th edition of the AJCC TNM staging system for gastric cancer using the National Cancer Database Ann Surg Oncol 24(12) 3683-3691 https://doi.org/10.1245/s10434-017-6078-x PMID: 28895113

15. Graziosi L, Marino E, and Donini A (2019) Survival comparison in gastric cancer patients between 7th and 8th edition of the AJCC TNM staging system: the first western single center experience Eur J Surg Oncol 45(6) 1105-1108 https://doi.org/10.1016/j.ejso.2018.12.010 PMID: $\underline{30595468}$ 
16. Schwarz RE and Smith DD (2007) Clinical impact of lymphadenectomy extent in resectable gastric cancer of advanced stage Ann Surg Oncol 14(2) 317-328 https://doi.org/10.1245/s10434-006-9218-2

17. Sun Z, Zhu GL, and Lu C, et al (2009) The impact of N-ratio in minimizing stage migration phenomenon in gastric cancer patients with insufficient number or level of lymph node retrieved: results from a Chinese mono-institutional study in 2159 patients Ann Oncol 20(5) 897-905 https://doi.org/10.1093/annonc/mdn707 PMID: 19179553

18. Zhou Y, Zhang J, and Cao S, et al (2013) The evaluation of metastatic lymph node ratio staging system in gastric cancer Gastric Cancer 16(3) 309-317 https://doi.org/10.1007/s10120-012-0190-1

19. Lu J, Wang W, and Zheng CH, et al (2017) Influence of total lymph node count on staging and survival after gastrectomy for gastric cancer: an analysis from a two-institution database in China Ann Surg Oncol 24(2) 486-493 https://doi.org/10.1245/s10434-016-5494-7

20. Pedrazzani C, Marrelli D, and Sivins A, et al (2010) Minimum number of removed and examined lymph nodes is essential in gastric cancer patients: reply to letter World J Surg 34(5) 1138-1139 https://doi.org/10.1007/s00268-010-0524-2 PMID: 20238214

21. Lu J, Zheng CH, and Cao LL, et al (2017) The effectiveness of the 8th American Joint Committee on Cancer TNM classification in the prognosis evaluation of gastric cancer patients: a comparative study between the 7th and 8th editions Eur J Surg Oncol 43(12) 23492356 https://doi.org/10.1016/j.ejso.2017.09.001 PMID: 28943179

22. Lee IS, Park YS, and Ryu MH, et al (2014) Impact of extranodal extension on prognosis in lymph node-positive gastric cancer Br J Surg 101(12) 1576-1584 https://doi.org/10.1002/bjs.9640 PMID: 25223244

23. Veronese N, Fassan M, and Wood LD, et al (2016) Extranodal extension of nodal metastases is a poor prognostic indicator in gastric cancer: a systematic review and meta-analysis J Gastrointest Surg 20(10) 1692-1698 https://doi.org/10.1007/s11605-016-3199-7 PMID: 27412320

24. Lee IS, Kang HJ, and Park YS, et al (2018) Prognostic impact of extranodal extension in stage 1B gastric carcinomas Surg Oncol 27(2) 299-305 https://doi.org/10.1016/j.suronc.2018.05.014 PMID: 29937185

25. Songun I, Putter $\mathrm{H}$, and Kranenbarg EM, et al (2010) Surgical treatment of gastric cancer: 15-year follow-up results of the randomised nationwide Dutch D1D2 trial Lancet Oncol 11(5) 439-449 https://doi.org/10.1016/S1470-2045(10)70070-X PMID: 20409751 